\title{
Genetic variants in humanin nuclear isoform gene regions show no association with coronary artery disease
}

\author{
Mall Eltermaa ${ }^{1^{*}}$ (D, Maili Jakobson ${ }^{1}$, Meeme Utt ${ }^{1,2}$, Sulev Kõks ${ }^{3,4}$, Reedik Mägi ${ }^{5}$ and Joel Starkopf ${ }^{6}$
}

\begin{abstract}
Objective: Coronary artery disease contributes to noncommunicable disease deaths worldwide. In order to make preventive methods more accurate, we need to know more about the development and progress of this pathology, including the genetic aspects. Humanin is a small peptide known for its cytoprotective and anti-apoptotic properties. Our study looked for genomic associations between humanin-like nuclear isoform genes and coronary artery disease using CARDIoGRAMplusC4D Consortium data.

Results: Lookup from meta-analysis datasets gave single nucleotide polymorphisms in all 13 humanin-like nuclear isoform genes with the lowest $P$ value for rs6151662 from the MTRNR2L2 gene including the $50 \mathrm{~kb}$ flanking region in both directions ( $P$-value $=0.0037$ ). Within the gene region alone the top variant was rs 78083998 from the MTRNR2L13 region (meta-analysis P-value $=0.042$ ). None of the found associations were statistically significant after correction for multiple testing. Lookup for expression trait loci in these gene regions gave no statistically significant variants.
\end{abstract}

Keywords: Humanin, Humanin-like, Coronary artery disease, Association study, Peptide

\section{Introduction}

Cardiovascular diseases account for most noncommunicable disease (NCD) deaths worldwide [1]. The WHO global action plan [1] for the years 2013-2020 aims to support and promote research in NCD to reduce the global burden via better prevention. Therefore, a lot of effort has been made to better understand the interplay of environmental, behavioural and genetic risk factors in order to make preventive methods more efficient.

Coronary artery disease (CAD) or ischaemic heart disease involves the reduction of blood flow to the heart muscle because of pathological process of atherosclerosis in coronary vessels. The typical presentations are angina pectoris, unstable angina, myocardial infarction and sudden cardiac death [2]. The genetic predisposition to CAD has received increasing attention. For example, in a recent study, 64 novel genetic risk loci for CAD were

\footnotetext{
*Correspondence: mall.eltermaa@ut.ee

${ }^{1}$ Institute of Biomedicine and Translational Medicine, University of Tartu, Tartu, Estonia

Full list of author information is available at the end of the article
}

identified, expanding the total to 161 [3]. There are genes known to have a large effect on, for example, lipoprotein metabolism (e.g. $L D L R$ ), resulting in increased risk of early-onset coronary disease [4]. However, CAD seems to be an omnigenic disease where all gene-regulatory networks may be interrelated and different tissues may contribute to disease progression [3].

In 2001, a novel gene cDNA, 99\% identical to the mitochondrially encoded 16S rRNA gene (MTRNR2), was reported to encode a short peptide-humanin $[5,6]$. Functionally, it was shown that this peptide binds with insulin-like growth factor-binding protein-3 (IGFBP-3) and Bax protein $[7,8]$. Additional studies have revealed that humanin has a cytoprotective function and a role in apoptosis regulation [5-8]. Regarding cardiovascular diseases, this peptide has been shown to be expressed in the endothelial layer of human blood vessels including the mammary artery, atherosclerotic coronary artery, and greater saphenous vein [9]. A lower circulating humanin level has been described in patients with coronary endothelial dysfunction compared to healthy controls [10].

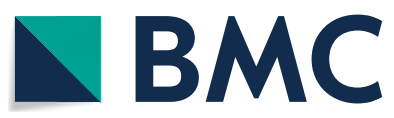

(c) The Author(s) 2019. This article is distributed under the terms of the Creative Commons Attribution 4.0 International License (http://creativecommons.org/licenses/by/4.0/), which permits unrestricted use, distribution, and reproduction in any medium, provided you give appropriate credit to the original author(s) and the source, provide a link to the Creative Commons license, and indicate if changes were made. The Creative Commons Public Domain Dedication waiver (http://creativecommons.org/ publicdomain/zero/1.0/) applies to the data made available in this article, unless otherwise stated. 
Data from Bodzioch et al. [11] suggested the existence of 13 nuclear-encoded humanin isoforms: humanin-like open reading frames named and numbered MTRNR2L1 to MTRNR2L13 after the original humanin MTRNR2 gene in the mitochondrial genome. This research also showed considerable gene homology between different species. The study showed that MTRNR2L1MTRNR2L10 were expressed variably in most human tissues, whereas MTRNR2 expression was considerably higher compared to the isoforms in all the studied tissues. MTRNR2, MTRNR2L1, MTRNR2L8 and MTRNR2L9 were highly expressed in the heart muscle suggesting their possible role in this tissue as cytoprotective peptides.

Most research has focused on humanin and its function. Studies done on several subjects have revealed differences in expression of humanin-like isoform genes and their regulation through hypoxia, miRNA or circRNA, to name some of these [12-19]. DNA copy number change in isoform genes has been found in arteries of patients with CHD and metabolic comorbidities [20]. A genome-wide association study on Huntington`s disease and copy number variation studies in classic heterotaxy and schizophrenia have identified variants in humaninlike isoform genes [21-23]. Humanin isoforms have also been studied as potential biomarkers for Alzheimer's disease-like dementia and Hirschsprung's disease, suggesting their wider role in physiological processes [24, 25]. Research on cancer subtypes, Dicer-binding genes, genomic mosaicism, extracellular RNA profiles, chromosomal rearrangements and huntingtin interactions has provided insight into networks in which humanin-like isoforms might be of importance [26-31].

Previously, we have shown changes in some humaninlike isoform expression levels in the context of cardiovascular disease [32]. This study design involved adult patients undergoing general anaesthesia before coronary artery bypass grafting; patients were randomly assigned to be ventilated with different $\mathrm{FiO}_{2} 60 \mathrm{~min}$ before operation. Exposure to $>96 \%$ oxygen upregulated two of the humanin-like peptide genes-MTRNR2L2 and MTRNR2L8-in the right atrial appendage tissue sample. Whether this change was the consequence of the different oxygen levels or whether there could be possible single nucleotide variations (SNVs) in isoform genes responsible for the observed effect after oxygen exposure, is not clear. Therefore, we decided to look for possible single nucleotide polymorphisms (SNPs) in gene regions of humanin-like peptides.

To study the possible association between coronary artery disease and genetic variation in humanin-like nuclear isoform peptide coding genes, we performed a lookup within all 13 humanin-like-peptide-coding genomic regions using publicly accessible meta-analysis data for coronary artery disease from the CARDIoGRAMplusC4D Consortium (Coronary ARtery DIsease Genome wide Replication and Meta-analysis (CARDIoGRAM) plus The Coronary Artery Disease (C4D) Consortium) [33]. We also analysed tissue-specific expression influences at the DNA level using data from the GTEx expression quantitative trait loci (eQTL) database [34].

\section{Main text Methods}

The aim of this study was to conduct a lookup from publicly available meta-analysis data on genetic associations between single nucleotide variants in 13 humanin-like nuclear isoform genes and coronary artery disease.

\section{Materials}

Genome-wide SNP association lookup was conducted using CARDIoGRAMplusC4D consortium data. This combines data from multiple large-scale genetic studies to identify risk loci for coronary artery disease and myocardial infarction [33, 35]. From the consortium we used two meta-analysis datasets to perform the lookup:

1. X-chromosome analysis dataset: Chromosome X-CAD [35] - meta-analysis of X-chromosomal variants for CAD including data from more than 43,000 CAD cases and 58,000 controls from 35 international study cohorts with random effects models. The $\mathrm{X}$-chromosome dataset was used for MTRNRL10 gene region lookup since it is located in the X-chromosome.

2. The second dataset was meta-analysis data of UK Biobank SOFT CAD GWAS (an interim release) with CARDIoGRAMplusC4D 1000 Genomes-based GWAS (i.e. dataset 4) and the Myocardial Infarction Genetics and CARDIoGRAM Exome (dataset 5) [33]. SOFT CAD phenotype was defined by the consortium as: fatal or nonfatal myocardial infarction, percutaneous transluminal coronary angioplasty or coronary artery bypass grafting, chronic ischemic heart disease, and angina. There were 10,801 cases and 137,914 controls.

eQTL analysis was carried out using the GTEx v7 data [34] from the GTEx Portal on 02/18/19 where lookup was conducted manually for all available tissues.

\section{Description of analysis}

For analysis we identified gene loci of 13 humanin-like nuclear isoform genes using the UCSC Genome Browser GRCh37/hg19 assembly [36]. We then performed a 
lookup for SNPs and eQTLs using the downloaded datasets.

1. SNP analysis:

a. The first analysis was done with the specific gene locus and the second analysis was done using the $50 \mathrm{~kb}$ flanking region in both directions.

b. As several variants were tested, multiple testing correction was used. The significance level for gene region analysis was calculated using Bonferroni correction; for the number of variants within the gene region it was $0.05 / 73=0.0007$, and for the analysis with flanking regions it was $0.05 / 4909=0.00001$.

2. eQTL analysis:

A lookup was performed from the database for all available tissues. eQTL results were combined with SNP analysis results for reporting the hits present in both analyses.

\section{Results}

We conducted a lookup for associations from 13 humanin-like nuclear isoform human gene regions located in different chromosomes using CARDIoGRAMplusC4D data $[33,35]$ (Table 1).

First, we looked for associations only within the regions of genes MTRNR2L1-MTRNR2L13, and second, we added $50 \mathrm{~kb}$ flanking regions in both directions to our lookup to extend the search for possible regulatory variants near these gene positions. The top variants for each region and from both lookups are shown in Table 2 . There were no statistically significant associations in

Table 1 Humanin-like nuclear isoform gene chromosomal position (GRCh37)

\begin{tabular}{llc}
\hline Gene & Chromosome & Position \\
\hline MTRNR2L1 & 17 & $22022437-22023991$ \\
MTRNR2L2 & 5 & $79945819-79946854$ \\
MTRNR2L3 & 20 & $55933496-55934878$ \\
MTRNR2L4 & 16 & $3421053-3422283$ \\
MTRNR2L5 & 10 & $57358750-57360488$ \\
MTRNR2L6 & 7 & $142374131-142375525$ \\
MTRNR2L7 & 10 & $37890366-37891859$ \\
MTRNR2L8 & 11 & $10529434-10530723$ \\
MTRNR2L9 & 6 & $62284008-62284534$ \\
MTRNR2L10 & $X$ & $55207824-55208944$ \\
MTRNR2L11 & 1 & $238107024-238108513$ \\
MTRNR2L12 & 3 & $96336030-96337067$ \\
MTRNR2L13 & 4 & $117220016-117221478$ \\
\hline
\end{tabular}

these gene regions after Bonferroni correction for the 73 variants found within the gene regions alone, nor for the 4909 variants found when these gene regions were searched with their added $50 \mathrm{~kb}$ flanking regions. The Bonferroni-corrected statistical significance limits were, respectively, $0.05 / 73=0.0007$ and $0.05 / 4909=0.00001$. The top variants within genes were rs78083998 from the MTRNR2L13 region (meta-analysis $\mathrm{P}$-value $=0.042$ ) and rs11004929 from the MTRNR2L5 region $(\mathrm{P}$-value $=0.10)$. For lookup with flanking regions, the top variants were rs6151662 from the MTRNR2L2 region $(\mathrm{P}$-value $=0.0037)$ and rs76836360 from the MTRNR2L8 region $(\mathrm{P}$-value $=0.0044)$.

Additionally, we looked for eQTL variants of genes MTRNR2L1-MTRNR2L13 from all available tissues using the GTEx database [34] and found 876 variants altogether. Out of these, 113 were present in CARDIoGRAMplusCD4D meta-analysis data. None of these exceeded the P-value threshold for Bonferroni multiple testing correction. The top marker was rs71476855 $(\mathrm{P}$-value $=0.008)$ from the MTRNR2L8 region. This variant showed eQTL association in thyroid tissue. Another marker, rs975494 from the MTRNR2L6 region, is an $\mathrm{eQTL}$ in lung tissue $(\mathrm{P}$-value $=0.047)$.

\section{Discussion}

The lookup study for genetic association between coronary artery disease and humanin-like isoforms focused on genetic variants in different humanin-like peptide genes, both in the gene region and within the $50 \mathrm{~kb}$ flanking region we investigated, although none were statistically significant after multiple testing correction. The top variants in the flanking region analysis were in the MTRNR2L2 and MTRNR2L8 gene regions. These same genes were overexpressed in our previous study, and MTRNR2L8 has, already earlier, been shown to be expressed in heart tissue [11,32]. Our results gave a possible eQTL SNP in the MTRNR2L8 gene, which did not obtain statistical significance. It is possible that these isoform genes contribute to the omnigenic development of $\mathrm{CAD}$, and factors influencing the expression of isoforms or the post-transcriptional and post-translational modification of isoforms may contribute to either the development or progression of CAD thereafter. Future studies should aim to answer these questions while specifying the role of humanin isoforms in cardiac cell metabolism, function and survival. Our study is the first that tries to answer whether single nucleotide variants in humaninlike nuclear isoform genes have an association with CAD.

The use of meta-analysis data from a multi-national consortium is one strength of this study. The number of participants is in the tens of thousands, which gives our study sufficient statistical power. Potential problem 


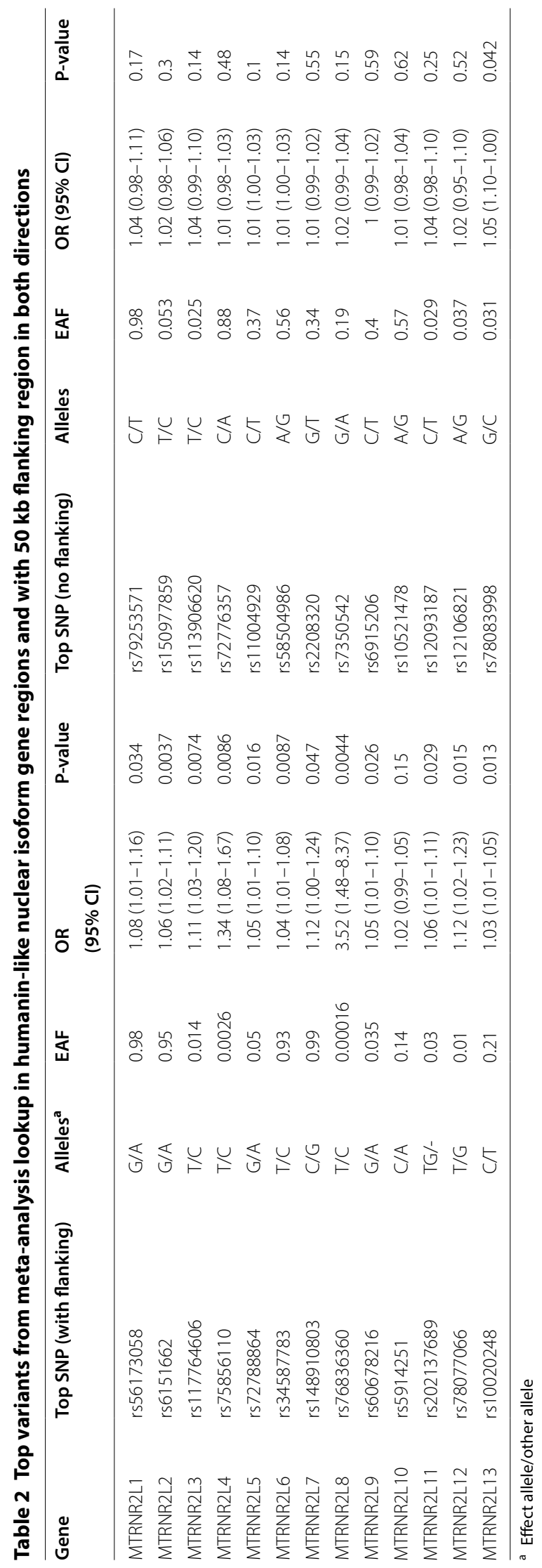


with phenotype association studies is that the definition of CAD is complicated due to differences in disease and symptom definitions, and coding systems. Furthermore, in this study, we only used the definition used by the original consortium, where CAD phenotype was defined as follows: fatal or nonfatal myocardial infarction, percutaneous transluminal coronary angioplasty or coronary artery bypass grafting, chronic ischemic heart disease and angina. It is possible that the results may differ when using a different phenotype definition.

Our study aimed to look for associations between DNA nucleotide variations in humanin-like nuclear isoform genes and established coronary heart disease. This lookup study showed no statistically significant associations between genetic variants in humanin nuclear isoform gene regions and coronary artery disease suggesting that these variants are not major contributors. They may influence disease development and progression in the omnigenic network.

\section{Limitations}

- as the used consortium data did not contain mitochondrial DNA data we were not able to look for possible associations in the MTRNR2 gene.

- We were only able to use the definition of CAD provided by the original consortium.

- Future studies should also address gender differences.

\begin{abstract}
Abbreviations
NCD: noncommunicable disease; CAD: coronary artery disease; IGFBP-3: insulin-like growth factor-binding protein-3; SNV: single nucleotide variant; SNP: single nucleotide polymorphism; eQTL: expression quantitative trait loci.
\end{abstract}

\begin{abstract}
Acknowledgements
Thanks go to Urmo Võsa for the eQTL lookup data. Thanks go to Triin Laisk for additional reading of the manuscript. Thanks go to Robert B. Davis for additional reading of the manuscript and its supplements. Thanks go to the Estonian Research Council for funding this work. The Genotype-Tissue Expression (GTEx) Project was supported by the Common Fund of the Office of the Director of the National Institutes of Health, and by NCI, NHGRI, NHLBI, NIDA, NIMH, and NINDS. Data on coronary artery disease/myocardial infarction have been contributed by CARDIoGRAMplusC4D investigators and have been downloaded from http://www.cardiogramplusc4d.org. Data on the X chromosomal analysis of coronary artery disease/myocardial infarction have been contributed by the referenced authors and has been downloaded from http://www.cardiogramplusc4d.org.
\end{abstract}

\section{Authors' contributions}

ME analysed the results and wrote the manuscript; RM, SK and JS designed the study; MJ and MU helped write the manuscript. All authors read and approved the final manuscript.

\section{Funding}

The study was supported by the Estonian Research Council (Grants PUT1160 and IUT20-46). The funding body played no role in the design of the study and collection, analysis, and interpretation of data and in the writing of the manuscript.

\section{Availability of data and materials}

the datasets analysed in this study are available for download on the CARDloGRAMplusC4D consortium website (http://www.cardiogramplusc4d.org/) and on the GTEx Portal website (https://gtexportal.org/home/).

\section{Ethics approval and consent to participate}

Not applicable.

\section{Consent for publication \\ Not applicable.}

\section{Competing interests}

The authors declare that they have no competing interests.

\section{Author details}

${ }^{1}$ Institute of Biomedicine and Translational Medicine, University of Tartu, Tartu, Estonia. ${ }^{2}$ Institute of Pharmacy, University of Tartu, Tartu, Estonia. ${ }^{3}$ Murdoch University, Murdoch, WA, Australia. ${ }^{4}$ Perron Institute for Neurological and Translational Science, Nedlands, WA, Australia. ${ }^{5}$ Institute of Genomics, University of Tartu, Tartu, Estonia. ${ }^{6}$ Department of Anaesthesiology and Intensive Care, Tartu University Hospital, Tartu, Estonia.

Received: 24 July 2019 Accepted: 14 November 2019

Published online: 21 November 2019

\section{References}

1. World Health Organization. Global action plan for the prevention and control of noncommunicable diseases iii who library cataloguing-inpublication data. World Health. 2013. p. 102. http://www.who.int/about /licensing/copyright_form/en/index.html\%5Cnhttp://apps.who.int/iris/ bitstream/10665/94384/1/9789241506236_eng.pdf?ua=1\%0Awww.who. int/about/licensing/copyright_form/en/index.html.

2. Sanchis-Gomar F, Perez-Quilis C, Leischik R, Lucia A. Epidemiology of coronary heart disease and acute coronary syndrome. Ann Transl Med. 2016;4(13):256.

3. van der Pim H, Niek V. Identification of 64 novel genetic loci provides an expanded view on the genetic architecture of coronary artery disease. Circ Res. 2018;122(3):433-43. https://doi.org/10.1161/CIRCRESAHA .117 .312086 .

4. Sarraju A, Knowles JW. Genetic testing and risk scores: impact on familial hypercholesterolemia. Front Cardiovasc Med. 2019:6(January):1-7.

5. Hashimoto Y, Ito Y, Niikura T, Shao Z, Hata M, Oyama F, et al. Mechanisms of neuroprotection by a novel rescue factor humanin from Swedish mutant amyloid precursor protein. Biochem Biophys Res Commun. 2001;283(2):460-8.

6. Tajima H, Niikura T, Hashimoto Y, Ito Y, Kita Y, Terashita K, et al. Evidence for in vivo production of Humanin peptide, a neuroprotective factor against Alzheimer's disease-related insults. Neurosci Lett. 2002;324(3):227-31.

7. Ikonen M, Liu B, Hashimoto Y, Ma L, Lee K-W, Niikura T, et al. Interaction between the Alzheimer's survival peptide humanin and insulin-like growth factor-binding protein 3 regulates cell survival and apoptosis. Proc Natl Acad Sci USA. 2003:100(22):13042-7.

8. Guo B, Zhai D, Cabezas E, Welsh K, Nouraini S, Satterthwait AC, et al. Humanin peptide suppresses apoptosis by interfering with Bax activation. Nature. 2003;423(6938):456-61.

9. Bachar AR, Scheffer L, Schroeder AS, Nakamura HK, Cobb LJ, Oh YK, et al. Humanin is expressed in human vascular walls and has a cytoprotective effect against oxidized LDL-induced oxidative stress. Cardiovasc Res. 2010;88(2):360-6.

10. Widmer RJ, Flammer AJ, Herrmann J, Rodriguez-Porcel M, Wan J, Cohen P, et al. Circulating humanin levels are associated with preserved coronary endothelial function. Am J Physiol Heart Circ Physiol. 2013;304(3):H393.

11. Bodzioch M, Lapicka-Bodzioch K, Zapala B, Kamysz W, Kiec-Wilk B, Dembinska-Kiec A. Evidence for potential functionality of nuclearly-encoded humanin isoforms. Genomics. 2009;94(4):247-56.

12. Bam M, Yang X, Zumbrun EE, Zhong Y, Zhou J, Ginsberg JP, et al. Dysregulated immune system networks in war veterans with PTSD is an outcome 
of altered miRNA expression and DNA methylation. Sci Rep. 2016;6:1-13. https://doi.org/10.1038/srep31209.

13. Baghbani F, Raoofian R, Hasanzadeh Nazarabadi M, Hamzehloei $\mathrm{T}$, Soukhtanloo M, Heidari M, et al. Identification of novel hypoxia response genes in Human Glioma cell line A172. Iran J Basic Med Sci. 2013;16(5):675-82.

14. Veilleux A, Mayeur S, Bérubé J-C, Beaulieu J-F, Tremblay E, Hould F-S, et al. Altered intestinal functions and increased local inflammation in insulin-resistant obese subjects: a gene-expression profile analysis. BMC Gastroenterol. 2015;15(1):119.

15. Quan L, Qiu T, Liang J, Li M, Zhang Y, Tao K. Identification of target genes regulated by KSHV miRNAs in KSHV-infected lymphoma cells. Pathol Oncol Res. 2015;21(4):875-80. https://doi.org/10.1007/s1225 3-015-9902-2.

16. Tao S, Liu YB, Zhou ZW, Lian B, Li H, Li JP, et al. miR-3646 promotes cell proliferation, migration, and invasion via regulating G2/M transition in human breast cancer cells. Am J TransI Res. 2016;8(4):1659-77.

17. Rull K, Mattila P, Reiman M, Sõber S, Laan M, llisson P. RNA sequencing of chorionic villi from recurrent pregnancy loss patients reveals impaired function of basic nuclear and cellular machinery. Sci Rep. 2016;6(1):1-14. https://doi.org/10.1038/srep38439.

18. Jiang Y, Wang Z, Liu S, Zhang N, Li X, Yang C, et al. Circular RNA circNOL10 Inhibits lung cancer development by promoting SCLM1-mediated transcriptional regulation of the humanin polypeptide family. Adv Sci. 2018;6(2):1800654.

19. Mei H, Zhang Y, Liu C, Zhang Y, Liu C, Song D, et al. Messenger RNA sequencing reveals similar mechanisms between neonatal and acute respiratory distress syndrome. Mol Med Rep. 2018;17(1):59-70.

20. Nazarenko MS, Sleptcov AA, Lebedev IN, Skryabin NA, Markov AV, Golubenko MV, et al. Genomic structural variations for cardiovascular and metabolic comorbidity. Sci Rep. 2017;7:1-9. https://doi.org/10.1038/srep4 1268

21. Costain G, Lionel AC, Merico D, Forsythe P, Russell K, Lowther C, et al. Pathogenic rare copy number variants in community-based schizophrenia suggest a potential role for clinical microarrays. Hum Mol Genet. 2013;22(22):4485-501.

22. Moss DJH, Tabrizi SJ, Mead S, Lo K, Pardiñas AF, Holmans P, et al. Identification of genetic variants associated with Huntington's disease progression: a genome-wide association study. Lancet Neurol. 2017;16(9):701-11.

23. Rigler SL, Kay DM, Sicko RJ, Fan R, Liu A, Caggana M, et al. Novel copynumber variants in a population-based investigation of classic heterotaxy. Genet Med. 2015;17(5):348-57.

24. Bik-Multanowski M, Pietrzyk JJ, Midro A. MTRNR2L12: a candidate blood marker of early Alzheimer's disease-like dementia in adults with down syndrome. J Alzheimer's Dis. 2015;46(1):145-50.

25. Du C, Xie H, Zang R, Shen Z, Li H, Chen P, et al. Apoptotic neuron-secreted HN12 inhibits cell apoptosis in Hirschsprung's disease. Int J Nanomed. 2016;11:5871
26. Gan Y, Li N, Zou G, Xin Y, Guan J. Identification of cancer subtypes from single-cell RNA-seq data using a consensus clustering method. BMC Med Genomics. 2018;11(Suppl 6):117. https://doi.org/10.1186/s1292 0-018-0433-z.

27. Hettne K, Goeman J, Roos M, van Zwet E, Hoen P, Mons B, et al. Common disease signatures from gene expression analysis in Huntington's disease human blood and brain. Orphanet J Rare Dis. 2016;11(1):1-13. https://doi. org/10.1186/s13023-016-0475-2.

28. Tsai S, Patel T, Boardman L, Wang Y, Dittmar R, Du M, et al. Plasma extracellular RNA profiles in healthy and cancer patients. Sci Rep. 2016;6(1):1-11. https://doi.org/10.1038/srep19413.

29. Vattathil S, Scheet P. Extensive hidden genomic mosaicism revealed in normal tissue. Am J Hum Genet. 2016;98(3):571-8. https://doi. org/10.1016/j.ajhg.2016.02.003.

30. White E, Schlackow M, Kamieniarz-Gdula K, Proudfoot NJ, Gullerova M. Human nuclear Dicer restricts the deleterious accumulation of endogenous double-stranded RNA. Nat Struct Mol Biol. 2014;21 (6):552-9.

31. Wu S, Jiang X, Zhao J, Ren M, Wang Y, Gao R, et al. Identification of recurrent and novel mutations by whole-genome sequencing of colorectal tumors from the Han population in Shanghai, eastern China. Mol Med Rep. 2018;18:5361-70.

32. Karu I, Tahepold P, Ruusalepp A, Reimann E, Koks S, Starkopf J. Exposure to sixty minutes of hyperoxia upregulates myocardial humanins in patients with coronary artery disease - a pilot study. J Physiol Pharmacol. 2015;66(6):899-906.

33. Nelson CP, Goel A, Butterworth AS, Kanoni S, Webb TR, Marouli E, et al. Association analyses based on false discovery rate implicate new loci for coronary artery disease. Nat Genet. 2017;49(9):1385-91. https://doi. org/10.1038/ng.3913.

34. Nicolae DL, Xi HS, Ongen H, Getz G, Dermitzakis ET, Aguet F, et al. Using an atlas of gene regulation across 44 human tissues to inform complex disease- and trait-associated variation. Nat Genet. 2018;50(7):956-67. https://doi.org/10.1038/s41588-018-0154-4.

35. Won H-H, Chambers JC, Kooner JS, Granger CB, Stewart AFR, Alver M, et al. No association of coronary artery disease with $\mathrm{X}$-chromosomal variants in comprehensive international meta-analysis. Sci Rep. 2016;6(1):1-9. https://doi.org/10.1038/srep35278.

36. James Kent W, Sugnet CW, Furey TS, Roskin KM, Pringle TH, Zahler AM, et al. The human genome browser at UCSC. Genome Res. 2002;12(6):996-1006.

\section{Publisher's Note}

Springer Nature remains neutral with regard to jurisdictional claims in published maps and institutional affiliations.

Ready to submit your research? Choose BMC and benefit from:

- fast, convenient online submission

- thorough peer review by experienced researchers in your field

- rapid publication on acceptance

- support for research data, including large and complex data types

- gold Open Access which fosters wider collaboration and increased citations

- maximum visibility for your research: over 100M website views per year

At BMC, research is always in progress.

Learn more biomedcentral.com/submissions 